\title{
An Autonomous Wall-Climbing Robot for Inspection of Reinforced Concrete Structures: SIRCAUR
}

\author{
Gabriela Gallegos Garrido and Tariq Pervez Sattar \\ London South Bank University, London South Bank Innovation Centre, \\ Granta Park, Great Abington, Cambridge CB21 6AL, UK
}

(Received 01 April 2021; Revised 02 July 2021; Accepted 06 July 2021; Published online 07 July 2021)

\begin{abstract}
A wall-climbing inspection robot has been designed to climb on safety-critical concrete structures by adhering to reinforcement steel bars (rebars) using permanent magnets to generate the adhesion forces. Simulation and experimental validation have been performed to determine the optimum flux focusing magnet configurations with the robot operating on $30-35 \mathrm{~mm}$ of concrete cover over rebars arranged in different patterns. The goal of adhesion force optimization is to be able to carry a ground-penetrating radar (GPR) sensor which detects rebar corrosion, concrete delamination, and concrete cover deterioration. The autonomous robot uses an ultra-wide band localization system and GPR data to control its motion trajectories to avoid regions where there is an insufficient density of rebars. Nondestructive testing (NDT) inspection data acquired by GPR are transmitted wirelessly to a ground station for processing and monitoring by NDT technicians.
\end{abstract}

Key words: climbing robot; GPR NDT; FEA; magnetic adhesion; reinforced concrete; UWB

\section{INTRODUCTION}

Corrosion of structures costs the UK economy approximately $3.5 \%$ of its gross domestic product annually [1] and results in $£ 100$ billion yearly for repairs and downtime. Automated methods of corrosion detection and timely repair can reduce the economic impact. Reinforced concrete $(\mathrm{R} / \mathrm{C})$ is used throughout the civil engineering industry for roads, bridges, high-rise buildings, dams, cooling towers, etc. Global corrosion repair costs for R/C are about $8 \%$ of all corrosion costs [2]. It is estimated that this is about $£ 8$ billion per annum in the UK alone. The $\mathrm{R} / \mathrm{C}$ inspection is mostly performed manually by constructing expensive scaffolding or by using ropes to reach a test site. The risk of accidents and falls can be reduced by using robotics to perform the inspection. Mobile robots must first provide access to test sites on large vertical surfaces before the inspection can be performed. Many types of wallclimbing robots have been developed for various tasks. Some survey papers capturing these developments are [3]-[5]. Wallclimbing robot research tries to increase payload capacity, mobility, and adhesion forces and to minimise energy consumption [6,7].

Wall-climbing robots have been developed for nondestructive testing [8], laser cutting for nuclear decommissioning [9], window cleaning [10], maintenance and inspection of vertical structures [11], inspection of petrochemical tanks [12], and wind turbine towers/blades [13].

The technology used by wall-climbing robots to create adhesion forces includes vacuum generating devices that use centrifugal pumps, turbines, and compressed air [14]. A review of electroadhesion technologies [15] and the problems of adhesion and locomotion of wall-climbing robots are described in [16]. The adhesion methods and materials for bio-inspired climbing robots

Corresponding authors: Gabriela Gallegos (e-mail: gallegog@1sbu.ac.uk); Tariq Pervez Sattar (e-mail: sattartp@lsbu.ac.uk). are described in [17]. Most problems of structural integrity have to do with large steel structures such as petrochemical storage tanks, ship hulls, bridges, monopiles, and wind turbine towers. On these structures, the best adhesion method is obtained by using permanent magnets or electromagnets. Wall-climbing robots using this method are reported in $[18,19]$.

The novel robotic development reported here, SIRCAUR, uses a permanent magnet climbing robot. It adheres to concrete reinforcement bars to reach test sites on vertical structures to detect rebar corrosion and delamination defects with $100 \%$ volume coverage. Tests have been performed on a concrete wall with rebars at depths of 30-35 $\mathrm{mm}$ from the surface. The design, prototyping, and testing of the robot are illustrated in this paper. The climbing robot was able to climb on concrete structures with rebar density at these depths, and the ground-penetrating radar (GPR) system was able to effectively detect defects.

This paper is the extension of a previously published conference article in [20]. The paper has been extended by including the design of our "flux focusing design toolbox", built as an application on top of COMSOL Multiphysics to assist the design of permanent magnet adhesion systems for climbing robots. Results of experiments to validate the Toolbox have been included. New experiments have been performed that validate our adhesion system designed for R/C structures. The following sections describe the crawler's design. Section II describes the design of the adhesion module. Section III describes the prototype and the submodules that comprise the crawler's payload. Finally, Section IV presents our conclusions.

\section{CRAWLER'S DESIGN: THE ADHESION MODULE}

To design climbing robots for industrial applications, it is important to consider the operating environment and the task to be carried out [6]. Robots that can climb on nonferrous surfaces tend to employ 
either suction cups or dynamic vortex adhesion methods which produce a vacuum with fast-spinning impellers. These methods require constant energy supply lines for long inspection times which result in long umbilical cables. To climb on structures constructed from ferrous materials, permanent magnets or electromagnets are preferred as they provide higher adhesion forces. Electromagnets control the adhesion force on demand but again require a constant energy supply to maintain adhesion to a structure. Permanent magnet adhesion is the best method for robots climbing on ferrous structures as the force is constant and can be engineered to be high with magnetic flux focusing techniques, does not need the application of power, and is fail-safe in the event of power failure to the rest of the robot.

SIRCAUR has been designed to use permanent magnets to adhere to reinforcement bars (rebars) buried in concrete and to use GPR to detect rebar corrosion and other concrete defects. The design of the climbing robot has attempted to increase payload capacity, mobility, adhesion safety, and to minimise energy consumption. Permanent magnets are used for the adhesion method for two reasons: (a) The method does not require energy consumption, therefore, avoiding the use of heavy batteries that will increase the payload. (b) In case of a power failure, the crawler will remain attached to the surface providing a safety feature. Our previous research to develop the technology to focus magnetic flux to couple with rebars buried in concrete and develop concrete climbing robots has been reported in [21-25].

The next subsections will explain the design of the crawler based on its adhesion module and payload.

\section{A. THE FLUX FOCUSING APP}

To design a robot that uses permanent magnets to adhere to rebars at a distance of $30-40 \mathrm{~mm}$ from the magnet system, it was necessary to first develop a design tool that predicts the adhesion force when flux focusing techniques are used with different magnet systems comprising different types of permanent magnets, yokes of different materials, and magnet placement configurations.

This section describes the development of the design tool used to select the best magnet system. Analysis of forces on a climbing robot on a vertical plane is given in [4].

Permanent magnet adhesion climbing robots developed for climbing on concrete structures are discussed in [6]. Engineering of these types of climbing robots remains a difficult trade-off challenge because increasing the payload target requires larger drive motors/gears which, in turn, increases the weight of the robot and requires more adhesion force to remain attached to a surface. Obtaining sufficient adhesion force to safely carry a target payload when the air gap between magnets and rebars is more than $30 \mathrm{~mm}$ is the major challenge. A numerical modeling optimization process was carried out to retrofit previously published adhesion mechanisms. To tackle the analysis of this problem, COMSOL Multiphysics was used to model the permanent magnet adhesion system.

Adhesion modules were investigated that used several permanent magnets and flux concentrators or "yokes" in different configurations to optimize the adhesion module to give a maximum adhesion force with a minimum weight of the module.

\section{B. SIMULATION OF ADHESION FORCE UNDER IDEAL CONDITIONS}

To ensure the reliability of modeling, an initial simulation was created to set up a model to compute the adhesion force of the magnets under ideal conditions. This means that the obtained results should match with the manufacturer's datasheet. Rare-earth neodymium magnets grade N52 and of size $50 \mathrm{~mm} \times 50 \mathrm{~mm}$ with $25 \mathrm{~mm}$ of thickness are used in the simulation (see Fig. 1). From their technical specifications, these magnets have a holding force of $116 \mathrm{~kg}$ when in flush contact with a mild steel surface.

This is one of the highest available magnet grades in the market. However, the weight of one magnet at $626 \mathrm{~g}$ is also high.

The model comprises one N52 magnet, one steel plate $(100 \mathrm{~mm} \times 100 \mathrm{~mm} \times 15 \mathrm{~mm})$, and one iron yoke of the same size as the plate.

With the geometry shown in Fig. 1 and with material properties listed in Table I, COMSOL simulations computed the force as $1156.8 \mathrm{~N}$ (close to specified magnet technical specifications, thus validating the model). It is shown in [8] that adding a yoke of high permeability to close the magnet circuit from one side results in a significant increase in adhesion force on the other side. The results showed that adding an iron yoke of the same size as the steel plate increases the force to $1663.3 \mathrm{~N}$. This model was used as a base model to build an App using the COMSOL Application Builder. The App window is shown in Fig. 2.

An optimization process was performed using COMSOL by varying the physical parameters of the magnet-yoke adhesion module [6]. The parameters that varied were the size of the magnet and relative permeability of the ferromagnetic structure. The air gap (distance between ferrous surface and magnet) is another important parameter to design an adhesion system for complex structures [6,7]. The best magnet configuration for maximum adhesion force [5] uses three magnets with $\mathrm{N}-\mathrm{S}-\mathrm{N}$ orientation placed on an iron yoke (Fig. 3).

The simulation model is composed of an iron yoke $(250 \mathrm{~mm} \times$ $50 \mathrm{~mm} \times 10 \mathrm{~mm}$, approximately $960 \mathrm{~g}$ net weight); three N52 rare-earth neodymium magnets are arranged on top of the yoke in an $\mathrm{N}-\mathrm{S}-\mathrm{N}$ configuration with $50 \mathrm{~mm}$ spacing.

Simulating this magnetic adhesion system (yoke + three magnets) placed over a $12 \mathrm{~mm}$ steel rebar with $30 \mathrm{~mm}$ of air gap (concrete cover) predicts an adhesion force of $143.1 \mathrm{~N}$. The magnetic flux lines are shown in Fig. 4. The simulation was validated with an in-house experimental test rig. Setup and results are explained next.

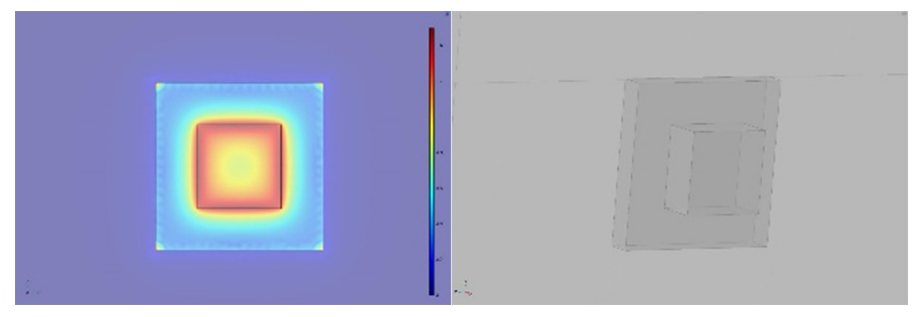

Fig. 1. Force analysis of N52 neodymium magnet under ideal conditions.

TABLE I. PROPERTIES USED TO INVESTIGATE ADHESION MODULES FOR COMSOL SIMULATION

\begin{tabular}{lc}
\hline Properties & Value \\
\hline Magnetic induction intensity $\mathrm{B}_{\mathrm{r}}(\mathrm{T})$ & 1.47 \\
Magnetic coercive force $\mathrm{H}_{\mathrm{cb}}(\mathrm{KA} / \mathrm{m})$ & 796 \\
Relative permeability of magnet $\left(\mu_{\mathrm{r}}\right)$ & 1.05 \\
Relative permeability of steel plate & 1000 \\
Relative permeability of iron yoke & 4500 \\
\hline
\end{tabular}




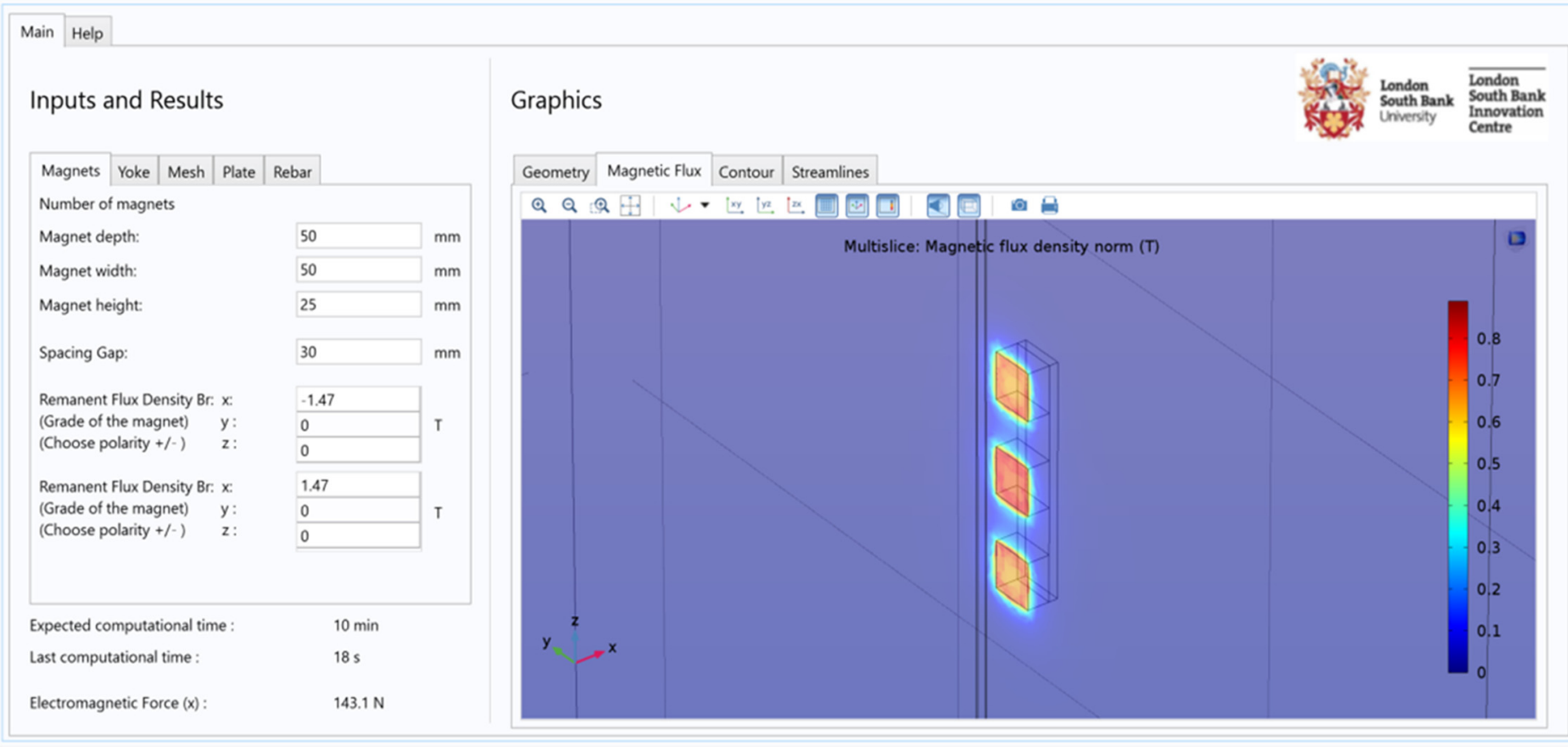

Fig. 2. FEA analysis using COMSOL App.

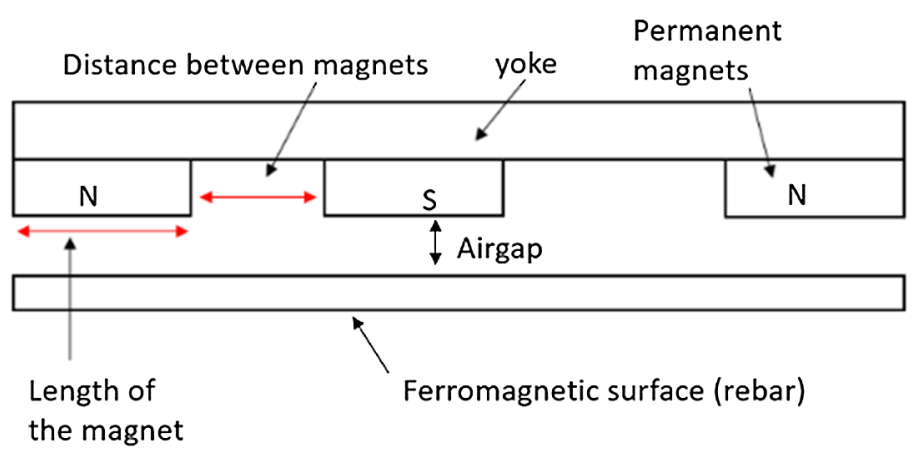

Fig. 3. Magnet yoke modeling layout.

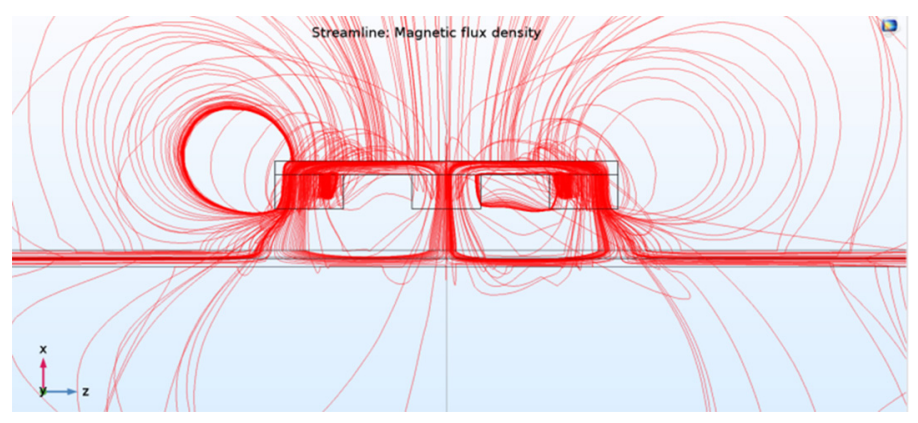

Fig. 4. Magnetic flux line behavior of three N52 magnets arranged N-S-N.

\section{EXPERIMENTAL RESULTS WITH IN-HOUSE TEST RIG}

Fig. 5 shows the positioning of the magnets on the yoke to construct the adhesion system simulated in Section II.B. The weight of the magnet system was $2.83 \mathrm{~kg}$, measured with an industrial scale.

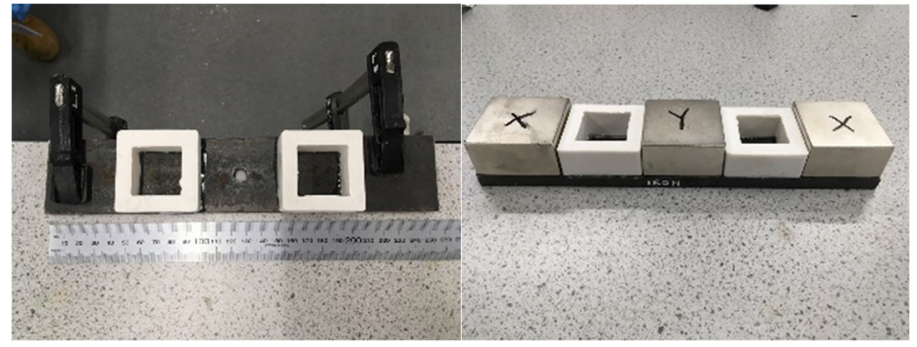

Fig. 5. Construction of the magnet system.

An attachment was added to the iron yoke to be able to fix it on the load cell machine that performed the force/tension test. The Instron 5567A B723 machine (capable of measuring forces up to $2 \mathrm{kN}$ ) was calibrated, and the test was conducted in accordance with ISO 7500-1:2015. The Instron procedure used was N001.

The magnet system was placed at $200 \mathrm{~mm}$ from the rebar on the load cell machine (see Fig. 6). The distance was slowly decreased while approaching a $12 \mathrm{~mm}$ diameter rebar until a $20 \mathrm{~mm}$ spacing gap was left between the magnets and the rebar. Measured force data were recorded (six values per second). Measurements were repeated for 16 and $20 \mathrm{~mm}$ diameter rebars.

For the sake of illustration, in the following sections, the results shown were performed on a $12 \mathrm{~mm}$ diameter rebar.

Most R/C structures have rebars within 30-35 mm beneath a concrete cover. However, concrete structures exposed to wet conditions have a concrete cover that can reach $50 \mathrm{~mm}$. Therefore, adhesion force was predicted with simulation and experimental measurement for the increasing air gap to the rebar (see Fig. 7).

As expected, the adhesion force decreases rapidly with an increasing air gap, from around $100 \mathrm{~N}$ at $35 \mathrm{~mm}$ to only $31.39 \mathrm{~N}$ at $50 \mathrm{~mm}$. Good agreement between experimental and COMSOL predictions validates the accuracy of the App. 

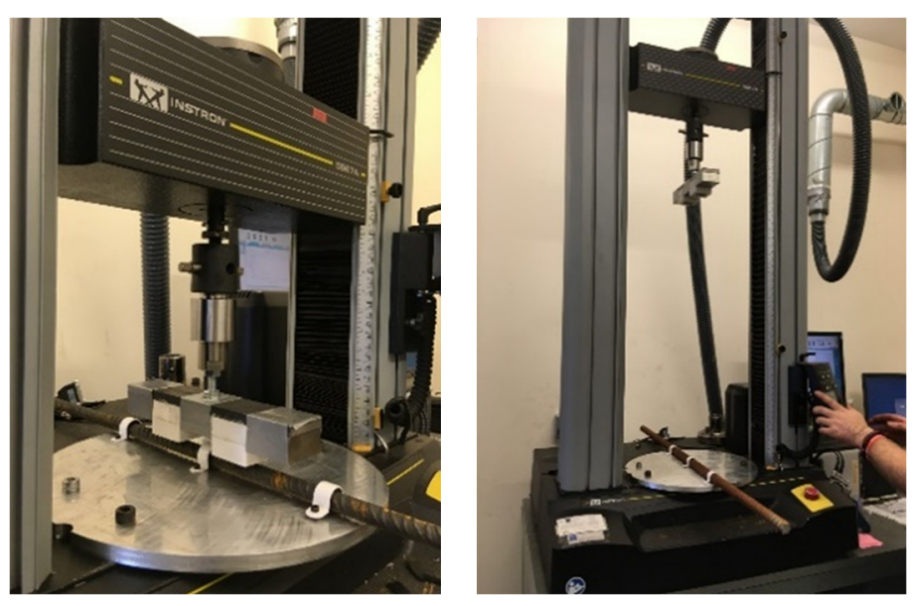

Fig. 6. In-house test rig using an Instron machine ( $2 \mathrm{kN}$ tension/ compression load cell).

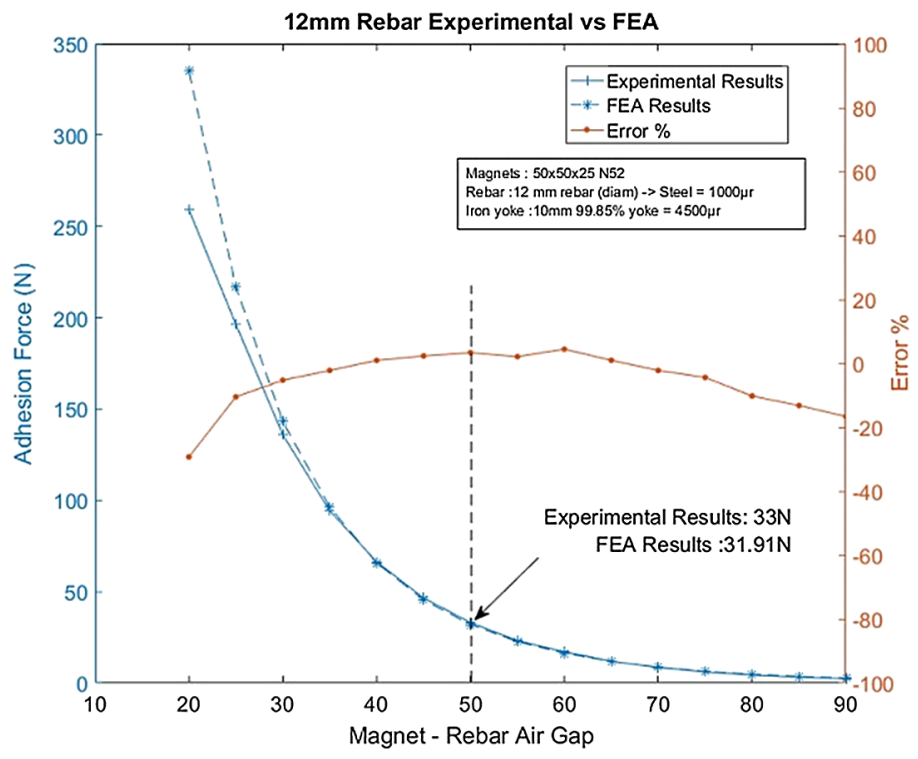

Fig. 7. Measured adhesion force and force predicted by FEA with COMSOL.

When the air gap was $30 \mathrm{~mm}$, a 5\% error was recorded. Minimum error was recorded when the air gap was $40 \mathrm{~mm}$ (i.e., min error of $0.91 \%$ ). Systematic errors can be the reason for the $\pm 5 \%$ error (i.e., when considering the air gap vs. forces, $\pm 1 \mathrm{~mm}$ can influence the adhesion force significantly). However, these results provide evidence to validate the COMSOL model and thus give confidence in the application.

\section{ROBOT R/C POTENTIAL WORKSPACE: SIMULATIONS AND TEST RIG}

In Section II.B, it is shown that the gap between the magnets and the rebars is the most important determinant of adhesion force. Nevertheless, other parameters such as the diameter, configuration of rebars (e.g., a mesh of rebars), and density of ferrous material also influence the adhesion force. British standard BS 850 and Eurocode [26] specify the minimum concrete cover over rebars for

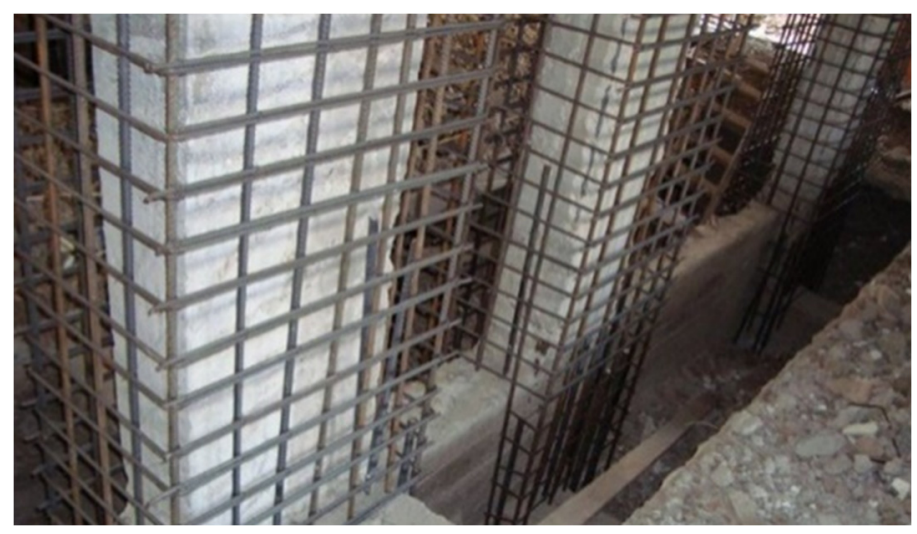

Fig. 8. Potential workspace for the climbing robot.

different environmental conditions. Most R/C structures are made of a mesh of rebars as shown in Fig. 8 .

The force estimation application is improved by adding the possibility to choose from a set of rebars (mesh) as the ferrous surface. The gap distance between the rebars and the magnet system (concrete cover) can be changed directly from the application.

For this experiment, four different sizes of mesh were tested (see Fig. 9) with three different concrete covers. To cover a large ferrous surface and to achieve the maximum adhesion force, it was decided to develop an arrangement of three yokes in parallel at a distance of $50 \mathrm{~mm}$ between them. Magnets were arranged in the same way as in Section II.B. The results are listed in Table II. As expected, the closer the ferrous surface is to the magnets, the greater is the adhesion force achieved.

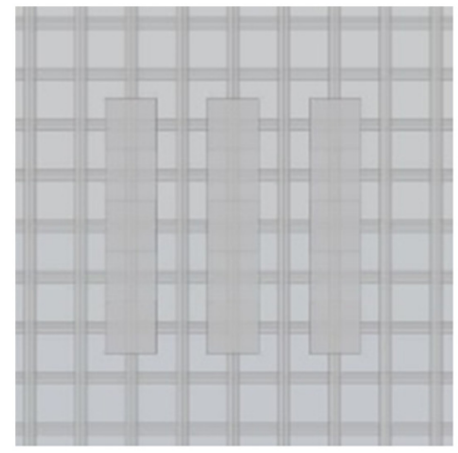

(a) $50 \times 50 \mathrm{~mm}$

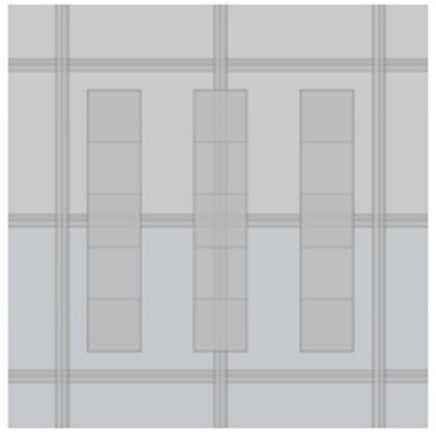

(c) $150 \times 150$

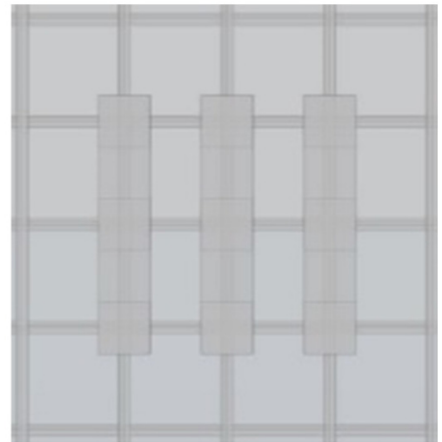

(b) $100 \times 100 \mathrm{~mm}$

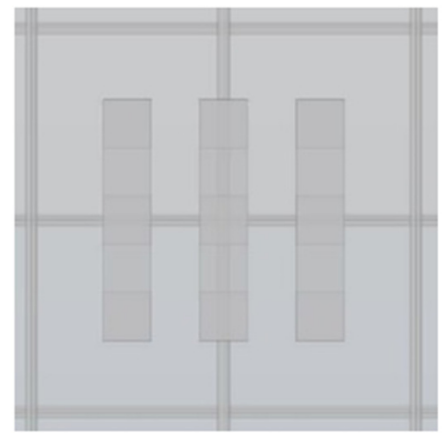

(d) $200 \times 200 \mathrm{~mm}$
Fig. 9. Rebar mesh spacing in four configurations. 
TABLE II. SIMULATION RESULTS WITH DIFFERENT MESH SIZES AND CONCRETE COVERS

\begin{tabular}{lccc}
\hline $\begin{array}{l}\text { Mesh space } \\
\mathbf{1 2} \mathbf{~ m m} \text { rebar }\end{array}$ & $\begin{array}{c}\text { Force at } \\
\mathbf{4 0} \mathbf{~ m m} \mathbf{( N )}\end{array}$ & $\begin{array}{c}\text { Force at } \\
\mathbf{3 5} \mathbf{~ m m} \mathbf{( N )}\end{array}$ & $\begin{array}{c}\text { Force at } \\
\mathbf{3 0} \mathbf{~ m m} \mathbf{( N )}\end{array}$ \\
\hline $200 \mathrm{~mm} \times 200 \mathrm{~mm}$ & 116.7 & 159 & 225.9 \\
$150 \mathrm{~mm} \times 150 \mathrm{~mm}$ & 145 & 192.6 & 263.3 \\
$100 \mathrm{~mm} \times 100 \mathrm{~mm}$ & 252.2 & 352.6 & 506.3 \\
$50 \mathrm{~mm} \times 50 \mathrm{~mm}$ & 287.9 & 391.4 & 546.8 \\
\hline
\end{tabular}

The aim of this experiment was to determine the type of rebar mesh where the robot will be able to climb as well as its payload capacity. To validate the simulation results, a magnet system consisting of three yokes was attached to aluminum brackets as shown in Fig. 10. The weight of this system was $10 \mathrm{~kg}$.

To measure adhesion forces, OMEGA mini load cells were attached to each of the four corners. Using an OMEGA summing box and a compatible meter, the total adhesion force applied by the magnet system was measured.

A dynamic rebar wall was constructed where it was possible to change the spacing between rebars. Three mesh configurations using $12 \mathrm{~mm}$ diameter rebars were made possible. The rebar meshes were covered with a fixed plywood board to simulate a concrete cover of $30 \mathrm{~mm}$ (the relative permeability of dry concrete is practically the same as air and wood). Load cell measurements were recorded with the constructed magnet system placed over the dynamic wall. Comparison of adhesion force measurements performed on the test rig results and predicted forces by FEA from the COMSOL simulation are tabulated in Table III.

If coefficient of friction is 0.5 and the total weight of the adhesion system is $10 \mathrm{~kg}$, an estimation of the robot's payload capacity is calculated in the last column of Table III. See analysis in [4].
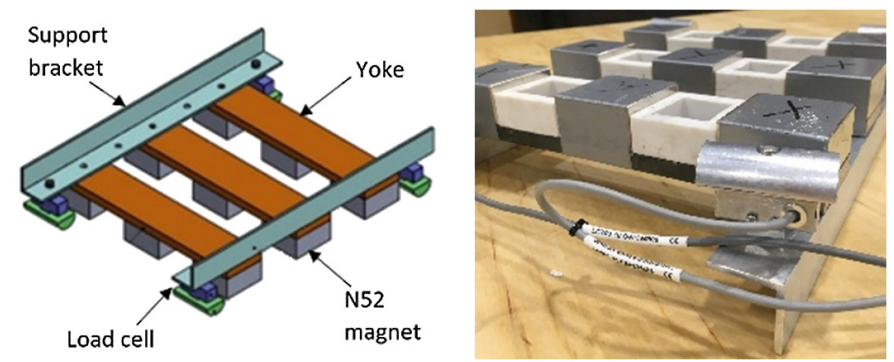

Fig. 10. Test rig construction with four load cells.

\section{TABLE III. ESTIMATION OF THE ROBOT'S WEIGHT WITH THE PROPOSED MAGNETIC ADHESION SYSTEM}

\begin{tabular}{lccc}
\hline $\begin{array}{l}\text { Mesh space } \\
\text { with 12 } \mathbf{~ m m} \\
\text { rebar }\end{array}$ & $\begin{array}{c}\text { FEA magnet } \\
\text { force (kg) }\end{array}$ & $\begin{array}{c}\text { Load cells } \\
\text { force (kg) }\end{array}$ & $\begin{array}{c}\text { Max payload } \\
\text { at } \mathbf{3 0} \mathbf{~ m m ~ ( k g )}\end{array}$ \\
\hline $200 \mathrm{~mm} \times 200 \mathrm{~mm}$ & 23.03 & 24.14 & 8.82 \\
$100 \mathrm{~mm} \times 100 \mathrm{~mm}$ & 51.62 & 50.91 & 22.20 \\
$50 \mathrm{~mm} \times 50 \mathrm{~mm}$ & 55.75 & 61.82 & 27.66 \\
\hline
\end{tabular}

\section{E. REAL ENVIRONMENT TESTING: CAR PARK}

Results from the above experiment give us the confidence to apply the adhesion system to a real-world environment. It is a well-known fact that the columns in multistory car parks are well reinforced.

Because a reliable method to determine the size of the rebars or their distance was not available, in the first instance, the system was placed on the column to verify that it remained stationary and stuck to the column. Once confirmed that the system was holding, additional weights were incrementally added to the system, as seen in Fig. 11, until the system started sliding.

Although it is not known how much ferrous material was embedded in the car park column, it was established that a robot using this adhesion system will be able to carry a payload of $7.6 \mathrm{~kg}$.

\section{CRAWLER'S DESIGN: THE PAYLOAD}

Structure of the physical robot, CAD design, is illustrated in Fig. 12. The adhesion module was positioned under the robot to coincide with the rebars. The design was optimized with a series of computer-aided design tasks to maintain a balance between the robot's physical parameters such as its weight, payload, and the adhesion strength of the magnet module.

\section{A. NDT MODULE: GPR}

The GPR is an effective NDT method for concrete structures. This technique has been commercially available since the 1970s, and numerous studies have been carried out since to develop it for a wide range of concrete inspection applications. It offers a unique technique to characterize surface and subsurface features. Different types of defects can be identified in rebars and overlaid R/C decks. It is also used for thickness measurement of concrete members, air void detection, inspection of vertical R/C structures, mapping of reinforcement bar locations, and measuring material properties of concrete [27,28]. GPR offers the advantage of high scanning speed and being lightweight $(<2 \mathrm{~kg})$ and is thus eminently suitable for deployment on a climbing robot. However, its limitations are that it cannot detect delamination, honeycombing, grouting defects, or measure variation of the quality of concrete. While other NDT methods can detect these defects, they are impractical for deployment on a climbing robot because of weight or because they can only be used in a static position.

The SIRCAUR project has used the PicoR-2K GPR for the NDT of concrete structures (specification shown in Table IV). The device is designed for subsurface sensing and monitoring of opaque materials. It enables calculation of the thickness of the layers inside such materials as well as detection and positioning of in-homogeneities within the material.

A laptop running the PicoR 4.3 software was connected via a USB-C cable to the PicoR-2K GPR. A concrete test block was manufactured (Fig. 13) with various known degrees of rebar thinning and various sizes of air void, embedded at known depths from the block surface. The concrete test rig block was manufactured, and tests were conducted by project partner TWI.

Three scanning sequences shown in Fig. 13 were used to detect (a) air voids: GPR moved in directions 1-3, A-B, and 2-4. These paths avoided the rebars but passed over the voids created within the concrete block; (b) rebars: GPR moved in directions 1-A-2 and 3-B-4. 


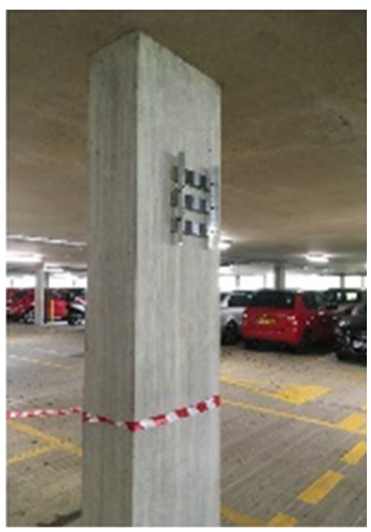

Magnet system

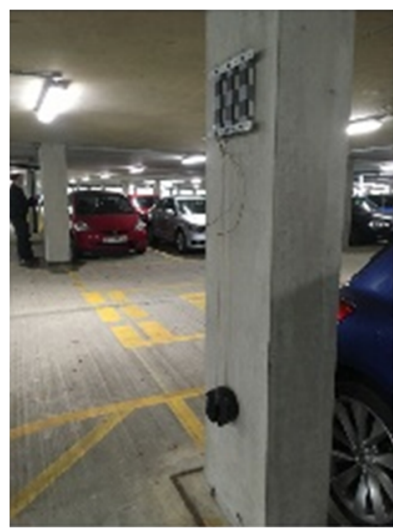

$50 \mathrm{~N}(5.098 \mathrm{~kg})$

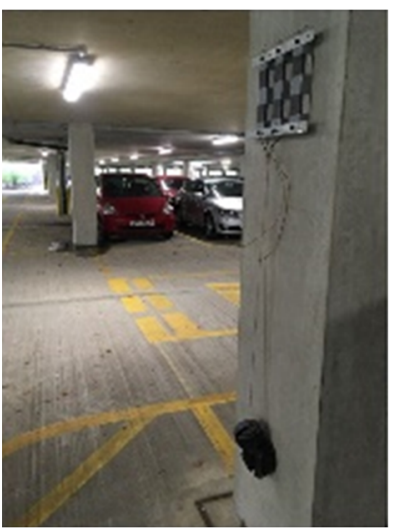

$70 \mathrm{~N}(7.138 \mathrm{~kg})$

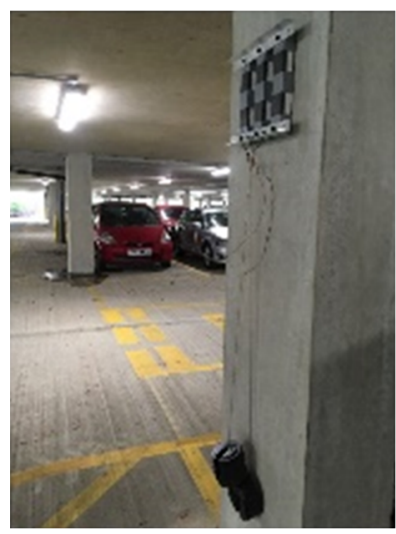

$75 \mathrm{~N}(7.647 \mathrm{~kg})$

-System start sliding-

Fig. 11. Test on a real reinforced concrete structure: car park column.

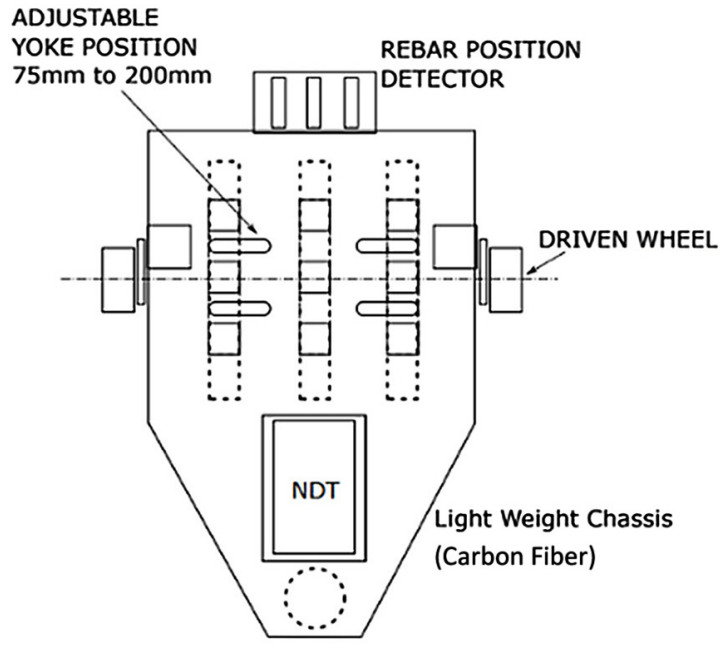

(a)
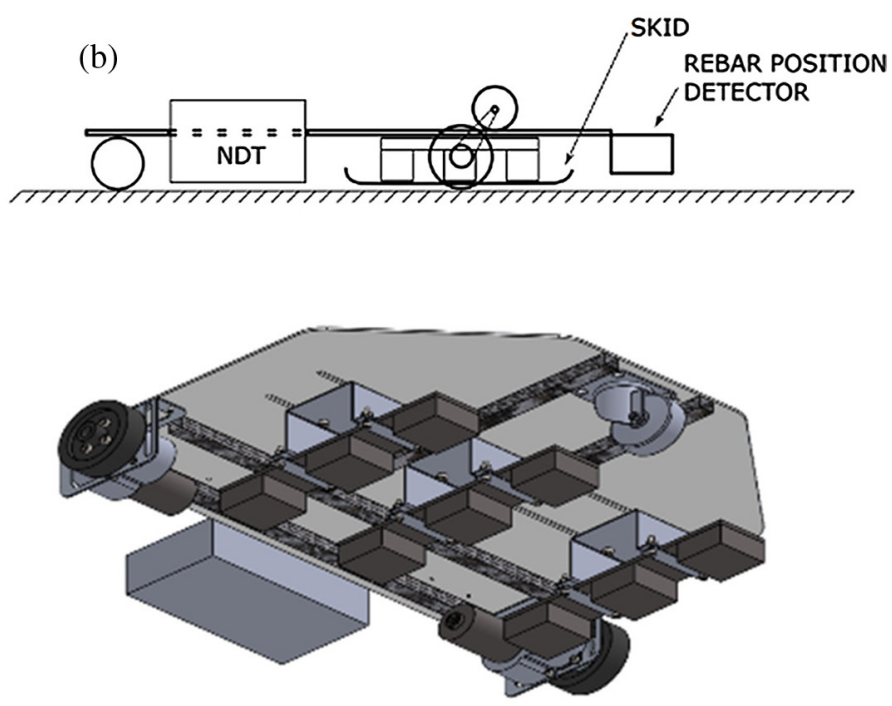

(c)

Fig. 12. (a) and (b) Schematic of the robot, (c) magnet system.

TABLE IV. PICOR-2K GPR SPECIFICATIONS

\begin{tabular}{ll}
\hline Parameter & \multicolumn{1}{c}{ Value } \\
\hline Frequency range (at a level of $-10 \mathrm{~dB})$ & $0.5-3.5 \mathrm{GHz}$ \\
Central frequency & $1600 \mathrm{MHz}$ \\
Pulse duration & $60 \mathrm{ps}$ \\
Pulse amplitude voltage & $6 \mathrm{~V}$ \\
Pulse repetition frequency & $50 \mathrm{MHz}$ \\
Range measurement accuracy & $1-2 \mathrm{~cm}$ \\
\hline
\end{tabular}

These paths avoided the voids but passed over rebar defects; (c) rebar and voids: GPR moved in the direction of 3-B-4 and then from 4-B-3. These trials evaluated the GPR with tightly spaced defects. Results are illustrated in Fig. 14.

Explanation of Fig. 14: (a) scan path A-B: four air voids detected in the scan line. Constant peak heights indicate that the
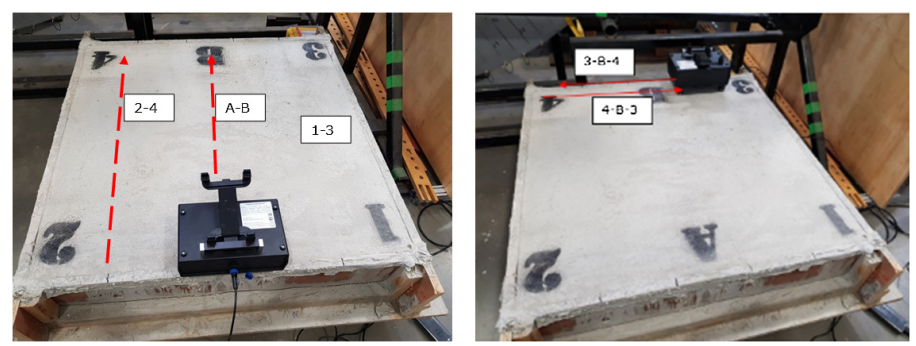

Fig. 13. (Left) Three scanning paths used to detect air voids. (Right) Scan paths 3-B-4 and 4-B-3 used to detect both air voids and rebars.

voids are at the same depth; (b) scan path 2-4 detects two of the three defects in the scan; (c) GPR scan detects four rebars in the concrete block (downward trend of the peaks indicates that the rebars are positioned at increasing depths); (d) scan path 4-B-3 detects both rebars and air voids. The upwards peak trend indicates 


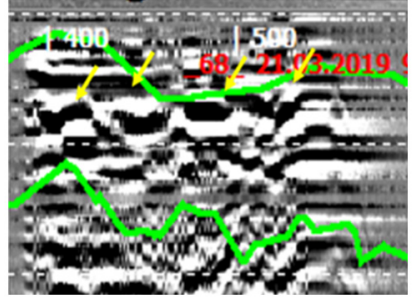

(a)

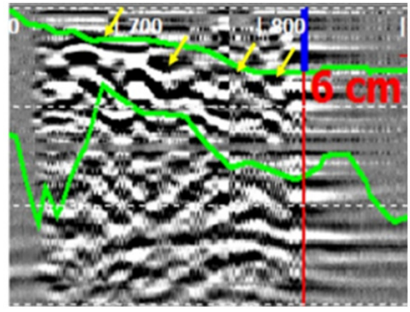

(c)

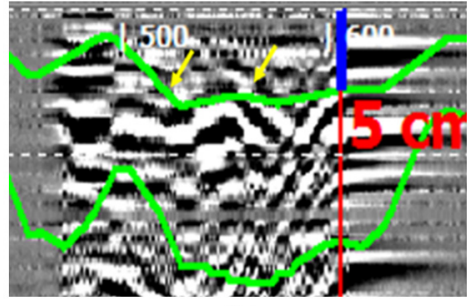

(b)

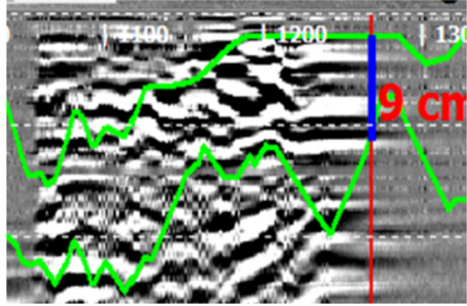

(d)
Fig. 14. (a) Scan path A-B, (b) scan path 2-4, (c) GPR detects four rebars, and (d) scan path 4-B-3.

that the scan moves from an area where the rebars and voids are at a lower position to an area where they are at a higher position.

\section{B. THE PROTOTYPE}

The climbing robot prototype is illustrated in Fig. 15. The design was performed by project partners InnotecUK with the support of TWI and LSBIC. The aim was to keep the whole robot payload including the electronics and the NDT system to less than $20 \mathrm{~kg}$. Therefore, the chassis of the robot was made of carbon fiber and aluminum alloy. The robot's control was robot operating system (ROS) enabled using a Raspberry Pi.

A laboratory test climbing surface was created by developing a wall with the same rebar spacing as the simulations. Fig. 17 shows

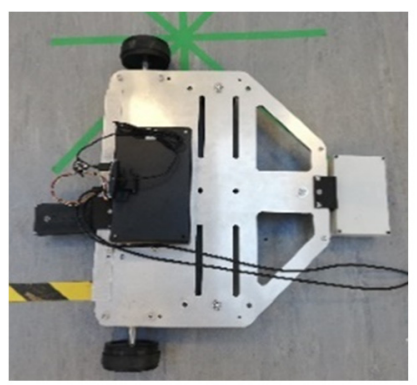

(a) Top view

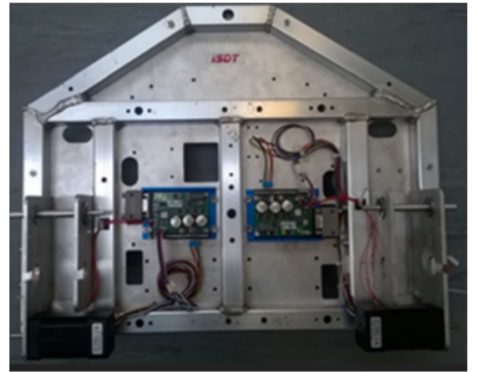

(b) Bottom view

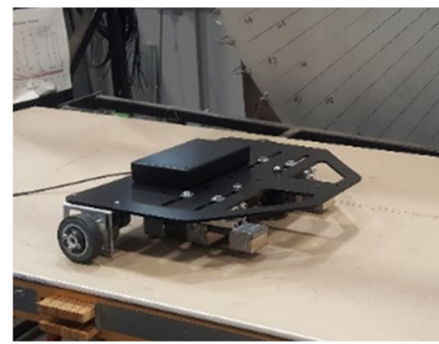

(c) Side view

Fig. 15. Climbing robot, top, bottom, and side views.
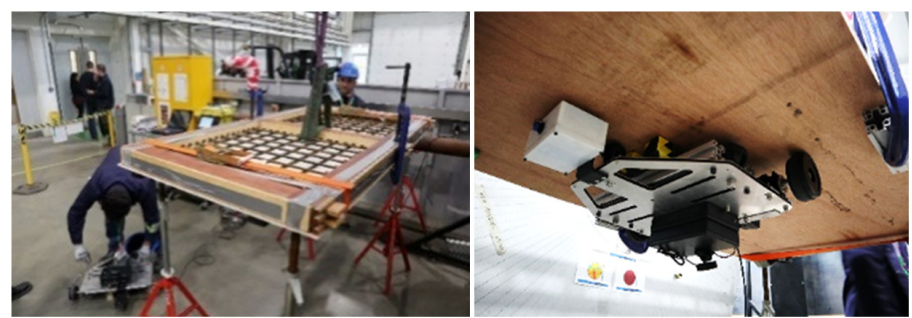

Fig. 16. (Left) The wall placed horizontally. (Right) Climbing robot on the wall showing that the adhesion force is sufficient to support the payload.

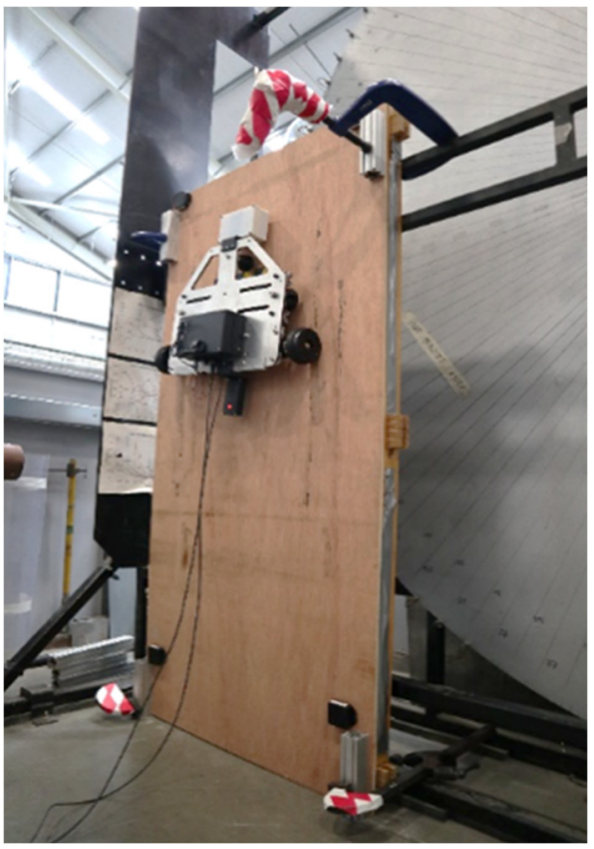

Fig. 17. Climbing robot tested on the vertical wall.

the dynamic wall (described in Section II.C) constructed to perform the trial test. Two climbing tests were conducted with the wall placed horizontally, and the climbing robot placed underneath as shown in Fig. 16, and the wall erected vertically as shown in Fig. 17.

The final configuration used for the trials was with $100 \mathrm{~mm} \times$ $100 \mathrm{~mm}$ rebar mesh and $12 \mathrm{~mm}$ diameter rebars. Trial with the crawler upside-down showed that the magnetic adhesion force provided by the permanent magnets was enough to support the weight of the SIRCAUR robot.

\section{THE LOCALIZATION MODULE}

A localization system was developed that used the ultra-wide band (UWB) localization technique to provide an accurate measurement of robot position on the wall. The system used the commercially available POZYX ${ }^{\mathrm{TM}}$ UWB module which was compatible with the operational microcontroller used for control purposes.

A ROS node was developed to incorporate the localization module into the robot's software architecture. The four beacons of the POZYX system can be seen in Fig. 17 at each of the four corners on the wall, which enabled the successful location of the robot on the wall. 


\section{CONCLUSION}

SIRCAUR is a lightweight, fast-moving climbing robot system for the inspection of $\mathrm{R} / \mathrm{C}$ structures which is easy to deploy and retrieve. The entire structure of robot is built with aluminum alloy and carbon fiber to make it lightweight. Robot structural integrity has been assured with a series of structural analysis experiments using CAD design software (SolidWorks) and FEA software (COMSOL). Adhesion force to carry the robot payload has been optimized by using configurations of neodymium 52 magnets placed on yokes of high permeability with force predictions made with COMSOL FEA simulations and validated experimentally.

A GPR NDT sensor has been incorporated into the system to detect the presence, location, and depth of rebar and air voids in a concrete structure. Laboratory trial tests on a wall engineered to simulate different rebar meshes and rebar depths indicate that the climbing robot can climb on concrete walls when the air gap between the magnet system and rebar is $30-35 \mathrm{~mm}$. The adhesion force generated by the permanent magnet system does not require an energy supply and is, therefore, advantageous for a climbing robot performing NDT on large concrete structures. The GPR system has been shown to detect rebars and air voids and measures both their position and depth.

\section{ACKNOWLEDGMENT}

Innovate UK grant (No. 103668) funded the SIRCAUR project with the following partners: London South Bank University (LSBU/LSBIC), Innovative Technology \& Science Ltd (InnotecUK), and TWI Ltd.

Full experimental video is available at $-w w w . y o u t u b e . c o m / w a t c h ?$ $v=n w V G V c n l y k 4$.

\section{REFERENCES}

[1] R. A. Market, "Infrastructure monitoring market by technology (wired and wireless), offering (hardware: sensors, data acquisition systems; software \& services), vertical (civil infrastructure, energy), application \& geography - global forecast to 2023," Research and Market, 2018.

[2] Lucintel, "Growth opportunities in the global inspection and testing equipment market in civil engineering 2013-2018: Trends, forecast, and opportunity analysis, July 2013," Lucintel Market Report, 2013.

[3] A. Hajeer, L. Chen, and E. Hu, "Review of classification for wall climbing robots for industrial inspection applications," in IEEE 16th Int. Conf. Autom. Sci. Eng., Hongkong, Aug. 2020, DOI: 10.1109/ CASE48305.2020.9216878.

[4] T. Seo, Y. Jeon, C. Park, and J. Kim, "Survey on glass and façadecleaning robots: Climbing mechanisms, cleaning methods, and applications," Int. J. Precis. Eng. Manuf. Technol., vol. 6, no. 2, pp. 367-376, DOI: 10.1007/s40684-019-00079-4.

[5] J. Xiao, H. Wang, H. Mengchu, Z. Li, and M. Weijnen, Advances in Climbing Robots, The Institute of Electrical and Electronics Engineers, Inc., April 2015, Wiley, DOI: 10.210.1002/9781119036821.ch22.

[6] M. F. Silva and T. J. Machado, "A survey of technologies and applications for climbing robots locomotion and adhesion," https:// www.intechopen.com/books/climbing-and-walking-robots/a-surveyof-technologies-and-applications-for-climbing-robots-locomotionand-adhesion, 2010, Accessed on: Apr. 15, 2020.

[7] G. G. Garrido, T. Sattar, M. Corsar, R. James, and D. Seghier, "Towards safe inspection of long weld lines on ship hulls using an autonomous robot," in CLAWAR Conf., Panama, 2018.

[8] M. Al Rashed, M. Kimball, L. Vega, D. Vera, J. Soler, M. Correa, A. Garcia, G. S. Virk, and T. Sattar, "Climbing robots for NDT applications," in 20th Int. Conf. Climbing and Walking Robots and Support Technologies for Mobile Machines, CLAWAR 2017, Porto, Portugal, 11-13 Sept. 2017.

[9] T. P. Sattar, P. Hilton, and M. O. F. Howlader, "Deployment of laser cutting head with wall climbing robot for nuclear decommissioning," in Proc. 19th Int. Conf. Climbing and Walking Robots and Support Technologies for Mobile Machines (CLAWAR 2016), World Scientific, London, United Kingdom, 2016, pp. 725-732.

[10] M. Vega-Heredia, et al., "Design and modelling of a modular window cleaning robot," Autom. Constr., vol. 103, pp. 268-278, 2019, DOI: 10.1016/j.autcon.2019.01.025.

[11] D. Schmidt and K. Berns, "Climbing robots for maintenance and inspections of vertical structures-A survey of design aspects and technologies," Robot. Auton. Syst., vol. 61, no. 12, pp. 1288-1305, 2013, DOI: 10.1016/j.robot.2013.09.002.

[12] M. G. Alkalla, M. A. Fanni, A. M. Mohamed, and S. Hashimoto, "Tele-operated propeller-type climbing robot for inspection of petrochemical vessels," Ind. Robot Int. J., vol. 44, no. 2, pp. 166-177, 2017, DOI: 10.1108/ir-07-2016-0182.

[13] A. Sahbel, A. Abbas, and T. Sattar, "System design and implementation of wall climbing robot for wind turbine blade inspection," in IEEE Int. Conf. Innov. Trends Comput. Eng. (ITCE), Aswan, Egypt, 2019, pp. 242-247, DOI: 10.1109/itce.2019.8646326.

[14] A. Brusell, G. Andrikopoulos, and G. Nikolakopoulos, "A survey on pneumatic wall-climbing robots for inspection," in IEEE Mediterr. Conf. Control Autom. (MED), Athens, Greece, 2016, pp. 220-225, DOI: $10.1109 / \mathrm{med} .2016 .7535885$.

[15] J. Guo, J. Leng, and J. Rossiter, "Electroadhesion technologies for robotics: A comprehensive review," IEEE Trans. Robot., vol. 36, no. 2, pp. 313-327, 2020, DOI: 10.1109/TRO.2019.2956869.

[16] N. S. Vlasova and N. V. Bykov, "The problem of adhesion methods and locomotion mechanism development for wall-climbing robots," 2019, arXiv Prepr. arXiv1905.09214.

[17] M. Elbadawi, G. Andrikopoulos, G. Nikolakopoulos, and T. Gustafsson, "Bio-inspired climbing robots in wet environments: recent trends in adhesion methods and materials," in IEEE Int. Conf. Rob. Biomim., Kuala Lumpur, Malaysia, 2018, pp. 2347-2353, DOI: 10. 1109/robio.2018.8665184.

[18] J. Shang, B. Bridge, T. Sattar, S. Mondal, and A. Brenner, "Development of a climbing robot for inspection of long weld lines," Ind. Robot, vol. 35, no. 3, pp. 217-223, 2008, DOI: 10.1108/ 01439910810868534.

[19] S. Hussain, T. Sattar, and E. Salinas, "Parameter analysis and design framework for magnetic adhesion wall climbing wheeled robot," Int. J. Intell. Syst. Technol. Appl., vol. 11, no. 1-2, pp. 102-116, 2012, DOI: 10.1504/IJISTA.2012.046546.

[20] G. Gallegos Garrido, M. Dissanayake, T. Sattar, A. Plastropoulos, and M. Hashim, "SIRCAUR: Safe inspection of reinforced concrete structures by autonomous robot," in CLAWAR Conf., Moscow, Russia, 2020.

[21] M. O. F. Howlader and T. P. Sattar, "Finite element analysis based optimization of magnetic adhesion module for concrete wall climbing robot," Int. J. Adv. Comput. Sci. Appl., vol. 6, no. 8, pp. 8-18, 2015.

[22] M. O. F. Howlader and T. P. Sattar, "Novel adhesion mechanism and design parameters for concrete wall-climbing robot," in IEEE Technically Co-sponsored SAI Intell. Syst. Conf. (IntelliSys), London, UK, 2015.

[23] M. O. F. Howlader and T. P. Sattar, "Development of magnetic adhesion based climbing robot for non-destructive testing," in Comput. Sci. Electron. Eng. Conf., University of Essex, UK, 2015. 
[24] M. O. F. Howlader, "Development of a wall climbing robot and ground penetrating radar system for non-destructive testing of vertical safety critical concrete structures," Ph.D. thesis, Lond. South Bank Univ., London, UK, 2016.

[25] M. O. F. Howlader, T. P. Sattar, and S. Dudley, "Development of a wall climbing robotic ground penetrating radar system for inspection of vertical concrete structures," in 18th Int. Conf. Control, Dyn. Syst. Robot, Amsterdam, The Netherlands, 2016.
[26] European Standard EN 1992, Eurocode 2, Design of concrete structures, general rules and rules for buildings, European Union, 2004.

[27] C. P. F. Ulricksen, "Application of impulse radar to civil engineering," Doctoral thesis, Dept. Eng. Geol., Lund Univ. Technol., Sweden, 1982.

[28] F. Tosti, C. Ferrante, "Using ground penetrating radar methods to investigate reinforced concrete structures," Surv. Geophys., vol. 41, pp. 485-530, 2020, DOI: 10.1007/s10712-019-09565-5. 